\title{
Metabolism in patients with small cell lung carcinoma compared with patients with non- small cell lung carcinoma and healthy controls
}

Agnes J Staal-van den Brekel, Annemie M W J Schols, Mieke A Dentener, Guul P M ten Velde, Wim A Buurman, Emiel F M Wouters

\begin{abstract}
Background - Weight loss is a frequently occurring problem in patients with lung cancer due to an increased resting energy expenditure (REE) and a decreased energy intake. The aim of the present study was to compare the metabolic and inflammatory characteristics of patients with small cell lung carcinoma (SCLC) and non-small cell lung carcinoma (NSCLC). The metabolic parameters of the lung cancer population were compared with those of a healthy control group.

Methods - REE was measured in 66 patients with lung cancer, subdivided according to their histology, and in 33 healthy controls matched for sex, age, and fat free mass (FFM). Inflammatory mediators were measured in the plasma of the patients with lung cancer.

Results - An increased REE adjusted for
\end{abstract} FFM was found in the patients with lung cancer. Those with small cell lung carcinoma (SCLC) had an increased REE adjusted for FFM (mean $1925 \mathrm{kcal} /$ day) compared with those with non-small cell lung carcinoma (NSCLC) (mean $1789 \mathrm{kcal} /$ day, $95 \%$ CI for difference 36 to 236). FFM accounted for $69 \%$ and $48 \%$ of the interindividual variation in REE in controls and those with NSCLC, respectively, while FFM accounted for only $25 \%$ of the variation in REE in patients with SCLC in whom the fat mass (FM) also contributed significantly (28\%) to the variation in REE. Increased concentrations of soluble TNFreceptor 75 (sTNF-R75) and cortisol were found in patients with SCLC compared with those with NSCLC. Lipopolysaccharide binding protein (LBP) and STNF-R55 were related to plasma levels of cortisol.

Conclusion - An enhanced REE adjusted for FFM occurred in patients with SCLC compared with those with NSCLC.

(Thorax 1997;52:338-341)

Keywords: resting energy expenditure, small cell lung cancer, inflammation.

PO Box 5800, 6202 AZ Maastricht, The Netherlands

Correspondence to: Dr A J Staal-van den Brekel.

Received 27 December 1995 Returned to authors 10 April 1996

Revised version received

19 December 1996

Accepted for publication

19 December 1996

Weight loss occurs frequently in patients with lung cancer ${ }^{1-3}$ as a result of a disturbance of the balance between energy intake and energy expenditure. We have shown that both an increased resting energy expenditure (REE) and a decreased energy intake relative to energy expenditure contribute to weight loss in patients with lung cancer. ${ }^{4}$ The central localisation of the tumour and enhanced systemic concentrations of inflammatory mediators are contributing factors to the increased REE. ${ }^{4}$

Lung cancer can be subdivided into two groups according to its histology: small cell lung carcinoma (SCLC) and non-small cell lung carcinoma (NSCLC). Hypermetabolism occurs in both groups ${ }^{5-8}$ and may be caused either by a direct effect of the tumour or as a consequence of secretion of hormones or cytokines. Cytokines are involved in metabolic disturbances in animals. ${ }^{9-11}$ We have previously described a relationship between the presence of a systemic inflammatory response (as assessed by measurement of both soluble (s) tumour necrosis factor (TNF) receptors and the acute phase proteins $\mathrm{C}$ reactive protein (CRP) and lipopolysaccharide binding protein (LBP)) with weight loss and hypermetabolism in patients with NSCLC. ${ }^{12}$ sTNF receptors are natural inhibitors of TNF- $\alpha$ and enhanced concentrations of the sTNF receptors in plasma reflect a systemic inflammatory response. ${ }^{13}$

The aim of the present study was to evaluate the metabolic and inflammatory characteristics of patients with SCLC and NSCLC. We hypothesised that the influence of inflammatory mediators on the enhanced REE might differ between the two groups. Metabolic parameters were also compared with a healthy control group.

\section{Methods}

PATIENTS AND HEALTHY CONTROLS

Thirty three patients with SCLC, 33 with NSCLC, and 33 healthy controls were included in the study. The three groups were matched for sex, age, and fat free mass (FFM). All patients had histologically documented tumours and had not yet received treatment. The exclusion criteria for the study were previous treatment with chemotherapy or radiotherapy, treatment with high doses of corticosteroids, severe endocrine abnormalities (insulin dependent diabetes mellitus, hyper/ hypothyroidism), and body temperature exceeding $37.7^{\circ} \mathrm{C}$. Tumour stage was assessed according to the international staging system for lung cancer. The TNM classification was used for NSCLC and the two stage classification system was used for SCLC. ${ }^{14}$ Healthy controls had a stable weight for more 
than one year, a body mass index (BMI) of $<30 \mathrm{~kg} / \mathrm{m}^{2}$, a normal body temperature, and no evidence of physical or mental disease as assessed by physical examination. The study was approved by the medical ethical committee of the University Hospital of Maastricht. Informed consent was obtained from all patients and controls.

RESTING ENERGY EXPENDITURE (REE) AND BODY COMPOSITION

REE was measured by indirect calorimetry using a ventilated hood system (Oxycon $\beta$, Mijnhardt, Bunnik, The Netherlands) as described previously. ${ }^{12}$ Measurements in patients were made at the metabolic ward over a 20 minute period between 07.00 hours and 09.00 hours under quiet conditions after an overnight fast in the hospital while at complete rest. Measurements in control subjects were performed similarly but on an outpatient basis. Variations due to limited physical activities do not significantly influence the measurement of REE. ${ }^{16}$ Body composition was assessed by bioelectrical impedance analysis as described previously. ${ }^{12}$

Weight loss was calculated as the difference between the reported stable weight before the illness (six months prior to investigation) and the actual weight. The control group had been weight stable for more than one year before measurement. REE was expressed in absolute terms (REE) and adjusted for FFM according to the method of Ravussin and Bogardus. ${ }^{17}$ The adjusted REE was calculated as the group mean REE plus measured REE minus predicted REE. The group REE is the mean absolute REE $(n=99)$, the measured REE is the resting metabolic rate in each subject, and the predicted REE is the calculated energy expenditure obtained by using the individual FFM in the linear regression equation of REE on FFM generated in the control group. Measured REE was also compared with predicted REE using the Harris-Benedict equations ${ }^{18}$ in order to allow comparison between this study and previous studies on REE in cancer patients. Subjects with a measured REE above $110 \%$ of that predicted by the Harris-Benedict formula were arbitrarily considered hypermetabolic.

MEASUREMENT OF INFLAMMATORY MEDIATORS Blood was obtained by venepuncture before breakfast. Plasma was separated by centrifugation and stored at $-70^{\circ} \mathrm{C}$ until analysis. Inflammatory mediators were measured using sandwich ELISA ${ }^{12}$ and CRP was measured by turbidimetry. The detection limit of the assay was $5 \mu \mathrm{g} / \mathrm{ml}$. We were not able to measure inflammatory mediators in plasma of the control group, but in a previous study control samples were obtained from 26 healthy elderly individuals. $^{12}$ The mean (SD) values of the inflammatory mediators in plasma of healthy controls were as follows: sTNF-R55 1.0 (0.3) $\mathrm{ng} / \mathrm{ml}$; sTNF-R75 $1.1(0.4) \mathrm{ng} / \mathrm{ml}$; LBP $8.6(3.1) \mu \mathrm{g} / \mathrm{ml}, \mathrm{CRP}<5 \mu \mathrm{g} / \mathrm{ml}$ and $\mathrm{TNF}-\alpha$ was not detectable.
BIOCHEMICAL PARAMETERS

Thyroid stimulating hormone was assessed with an immunoradiometric assay and cortisol was determined by a radioimmunoassay. Plasma creatinine levels were used as a renal function parameter and were detected by the modified Jassé reaction (Dimension, Dupont, France). ${ }^{19}$

PULMONARY FUNCTION

Forced expiratory volume in one second $\left(\mathrm{FEV}_{1}\right)$ and inspiratory vital capacity (IVC) were measured with a wet spirometer (Pulmonet III; Gould Godart, Bilthoven, The Netherlands). The highest value of at least three technically acceptable spirometric manoeuvres was used and the values were expressed as percentages of the reference values. ${ }^{20}$

ANALYSIS OF DATA

Statistical analyses were performed using the Student's $t$ test when appropriate, adjusted for multiple testing according to the method of Bonferroni. The Mann-Whitney $U$ test was used for non-parametric data. Since impaired renal clearance leads to increased concentrations of sTNF receptor, ${ }^{21}$ the plasma concentrations of sTNF-R55 and sTNF-R75 were analysed together with serum creatinine levels. An analysis of covariance was therefore performed using plasma creatinine levels as a covariable with sTNF-R55 and sTNF-R75 as factors in the statistical model. Frequency data were compared using the $\chi^{2}$ test. Correlations were determined using the Pearson correlation coefficient. Results are presented as mean (SD). $p$ values of $<0.05$ were considered statistically significant. The statistical calculations were performed using the SPSS/PC +4.0 package. $^{22}$

\section{Results}

BASELINE CHARACTERISTICS

Each group consisted of 24 men and nine women (table 1). No differences were found in body weight or BMI among the three groups. Ten patients with SCLC and 11 with NSCLC presented with more than $10 \%$ weight loss from their pre-illness weight. No significant differences in lung function parameters were found between the two groups of cancer patients. Cortisol concentrations were significantly enhanced in patients with SCLC compared with those with NSCLC (table 1), although the mean concentration of cortisol was within the normal range $(200-700 \mathrm{nmol} /$ 1).

\section{RESTING ENERGY EXPENDITURE}

REE adjusted for FFM was significantly higher in patients with lung cancer than in healthy controls (mean difference $214 \mathrm{kcal} /$ day, 95\% CI 133 to 295; table 2). When the lung cancer population was divided according to tumour type REE adjusted for FFM was significantly higher in those with SCLC than in those with 
Table 1 Mean (SD) study parameters of the three groups

\begin{tabular}{lccl}
\hline & $\begin{array}{c}S C L C \\
(n=33)\end{array}$ & $\begin{array}{c}\text { NSCLC } \\
(n=33)\end{array}$ & $\begin{array}{l}\text { Controls } \\
(n=33)\end{array}$ \\
\hline M/F & $24 / 9$ & $24 / 9$ & $24 / 9$ \\
Age (years) & $63(10)$ & $65(8)$ & $66(8)$ \\
Weight (kg) & $69.7(11.6)$ & $68.9(11.0)$ & $73.8(10.7)$ \\
FFM (kg) & $48.6(6.0)$ & $48.7(5.9)$ & $51.0(7.1)$ \\
FM (kg) & $21.1(8.4)$ & $20.3(7.8)$ & $22.7(7.5)$ \\
Weight loss $\geq 10 \%(\mathrm{n})$ & 10 & 11 & 0 \\
BMI (kg/m $)^{2}$ & $24.4(3.2)$ & $23.8(3.6)$ & $25.4(3.2)$ \\
Weight loss (\%) & $6.2(6.0)$ & $5.0(7.1)$ & $0(0)$ \\
TSH (mU/l) & $3.3(3.6)$ & $2.6(2.3)$ & NT \\
Cortisol (nmol/l) & $569(179)^{*}$ & $470(170)$ & NT \\
IVC (\%) & $86.6(23.4)$ & $93.2(18.8)$ & NT \\
FEV $(\%)$ & $76.3(24.8)$ & $75.3(23.2)$ & \\
Tumour stage (NSCLC) & & 13 & \\
$\quad$ Stage I and II (n) & & 4 & \\
Stage IIIA & & 5 & \\
Stage IIIB & & & \\
Stage IV & & & \\
Tumour stage (SCLC) & 10 & & \\
$\quad$ Limited & 23 & & \\
$\quad$ Extensive & & & \\
\hline
\end{tabular}

SCLC $=$ small cell lung carcinoma, NSCLC $=$ non-small cell lung carcinoma, FFM $=$ fat free mass; $\mathrm{FM}=$ fat mass; $\mathrm{n}=$ number of subjects; $\mathrm{BMI}$ = body mass index; $\mathrm{TSH}=$ thyroid stimulating hormone; IVC = inspiratory vital capacity; $\mathrm{FEV}_{1}=$ forced expiratory volume in one second; $\mathrm{NT}=$ not tested.

$* \mathrm{p}<0.05$, SCLC versus NSCLC.

Table 2 Comparison of mean (SD) metabolic parameters between the three groups

\begin{tabular}{lllll}
\hline & $\begin{array}{l}\text { Total patients } \\
(n=66)\end{array}$ & $\begin{array}{l}\text { SCLC } \\
(n=33)\end{array}$ & $\begin{array}{l}\text { NSCLC } \\
(n=33)\end{array}$ & $\begin{array}{c}\text { Controls } \\
(n=33)\end{array}$ \\
\hline REE (kcal/day) & $1691(255)^{*}$ & $1758(270) \ddagger$ & $1624(224)$ & $1546(248)$ \\
Adjusted REE (kcal/day) & $1857(213)^{* *}$ & $1925(238) \dagger+\neq \ddagger$ & $1789(162) \Phi$ & $1643(138)$ \\
REE (\%HB) & $120(14)^{* *}$ & $124(14) \neq \ddagger$ & $116(14)$ & $105(9)$ \\
\hline
\end{tabular}

$\mathrm{REE}=$ resting energy expenditure; $\mathrm{HB}=$ Harris Benedict.

$* \mathrm{p}<0.01 ; * * \mathrm{p}<0.001$, total group versus controls; $\dagger \mathrm{p}<0.025, \neq \neq \mathrm{p}<0.01$, SCLC versus NSCLC;

$\ddagger \mathrm{p}<0.005, \ddagger \neq \mathrm{p}<0.001$, SCLC versus controls; $\mathbb{\mathrm { p }}<0.001$, NSCLC versus controls.

Table 3 Mean (SD) concentrations, medians and range of patients with small cell carcinoma (SCLC) and those with non-small cell lung carcinoma (NSCLC)

\begin{tabular}{|c|c|c|c|}
\hline & $\operatorname{SCLC}(n=23)$ & $\operatorname{NSCLC}(n=23)$ & $p$ value \\
\hline sTNF-R55 (ng/ml)* & $\begin{array}{l}1.6(0.9) \\
1.4 \\
0.4-3.9\end{array}$ & $\begin{array}{l}1.2(0.7) \\
1.0 \\
0.3-3.0\end{array}$ & 0.10 \\
\hline sTNF-R75 (ng/ml)* & $\begin{array}{l}2.3(1.3) \\
2.0 \\
0.8-5.4\end{array}$ & $\begin{array}{l}1.6(0.4) \\
1.5 \\
1.0-2.2\end{array}$ & $<0.05$ \\
\hline $\mathrm{LBP}(\mu \mathrm{g} / \mathrm{ml})$ & $\begin{array}{c}18.9(8.0) \\
18.1 \\
8.4-43.5\end{array}$ & $\begin{array}{c}1.0(12.1) \\
15.4(1 \\
3.0-46.9\end{array}$ & 0.43 \\
\hline $\mathrm{CRP}(\mu \mathrm{g} / \mathrm{ml})$ & $\begin{array}{l}34(36) \\
17 \\
5-144\end{array}$ & $\begin{array}{l}34(36) \\
13 \\
5-145\end{array}$ & 0.82 \\
\hline
\end{tabular}

* Analysis of covariance adjusted for plasma creatinine. sTNF-R55, sTNF-R75 = soluble TNF receptors 55 and $75 ; \mathrm{LBP}=$ lipopolysaccharide binding protein; $\mathrm{CRP}=\mathrm{C}$ reactive protein.

NSCLC (mean difference $136 \mathrm{kcal} /$ day, $95 \%$ CI 36 to 236).

FFM accounted for $69 \%(\mathrm{p}<0.001)$ and $\mathrm{FM}$ for $7 \%(\mathrm{p}<0.01)$ of the interindividual variation in REE in the healthy control group. In the NSCLC population FFM accounted for $48 \%$ $(p<0.001)$ and $F M$ for $3 \%(p>0.05)$ of the interindividual variation in REE. However, in the SCLC population the prediction of REE by body composition showed a different pattern with FFM accounting for only $25 \%(\mathrm{p}=0.01)$ of the interindividual variation in REE while FM accounted for $28 \%(\mathrm{p}<0.001)$.

EFFECT OF TUMOUR STAGE

To investigate the influence of tumour stage in SCLC the patients were divided into those with limited disease $(n=10)$ and those with extensive disease $(n=23)$ (data not shown). No differences could be detected in metabolic parameters between the two populations.
INFLAMMATORY MEDIATORS

Levels of sTNF-R75 were significantly increased in the patients with SCLC compared with those with NSCLC (mean difference $0.7 \mathrm{ng} / \mathrm{ml}, 95 \%$ CI 0.1 to 1.3 ), but no difference was seen in levels of sTNF-R55, LBP, or CRP, while TNF- $\alpha$ was not detectable (table 3 ). The levels of sTNF-R55 and LBP were related to cortisol levels $(r=0.42, \mathrm{p}<0.01 ; r=0.52$, $\mathrm{p}<0.001$, respectively). No significant correlation was found for sTNF-R75 $(r=0.20)$ or CRP $(r=0.33)$.

\section{Discussion}

The aim of this study was to compare the metabolic and inflammatory characteristics of patients with lung cancer subdivided according to tumour type. An enhanced REE adjusted for FFM was found in patients with SCLC compared with those with NSCLC matched for sex, age, and FFM. In addition, patients with lung cancer had an increased REE adjusted for FFM compared with healthy controls matched for sex, age, and FFM.

An increase in REE compared with predicted values has been reported previously in patients with lung cancer. ${ }^{4-8}$ Although total energy expenditure is the sum of REE, diet induced thermogenesis, and activity related energy consumption, most studies have focused on REE measurements. Few studies have looked at the occurrence of hypermetabolism in patients with SCLC. ${ }^{56} \mathrm{Jebb}$ et $a l^{6}$ recently found an enhanced REE adjusted for FFM in patients with SCLC but they did not investigate possible reasons for the enhanced REE. Patients with SCLC had an increased REE adjusted for FFM compared with those with NSCLC and healthy controls. Subdivision of SCLC according to tumour stage revealed that tumour stage did not influence metabolic parameters in SCLC as confirmed by Russell et al. ${ }^{5}$ To investigate the clinical relevance of the observed increase in REE to the pathogenesis of weight loss in lung cancer, the expected weight loss over a six month period was calculated. A recently developed computer simulation model was used ${ }^{23}$ to calculate the expected weight change in a man aged 65 years of height $170 \mathrm{~cm}$ and weight $65 \mathrm{~kg}$ with REE amounting to $113 \%$ of predicted. It was found that an increase in REE of this amount would result in a weight loss of $7 \%$ which corresponds well with the results of this study.

In order to explain the differences in REE, factors contributing to REE were investigated. Firstly, the influence of body composition on REE was analysed. FFM accounted for $69 \%$ and $48 \%$ of the interindividual variation in REE in controls and patients with NSCLC, respectively, while FFM accounted for only $25 \%$ of the variation in REE in patients with SCLC. However, FM accounted for $28 \%$ of the variation in REE in patients with SCLC and was a significant covariate in the significant difference in REE observed between patients with NSCLC and those with SCLC. These findings could indicate changes in carbohydrate 
compared with fat metabolism specifically related to SCLC.

In addition, the influence of systemic concentrations of inflammatory mediators on REE was investigated. $\mathrm{TNF}-\alpha$, interleukin (IL) -1 and IL- 6 were detected in animal models with cachexia. $^{9-11}$ Biologically active $\mathrm{TNF}-\alpha$ is difficult to detect because of its short half life and the formation of complexes with the STNF receptors. ${ }^{24}$ The plasma concentrations of both sTNF receptors were therefore measured and both were increased in patients with NSCLC. ${ }^{12}$ In the present study the systemic concentrations of sTNF-R75 were enhanced in patients with SCLC compared with NSCLC, while no differences in sTNF-R55, LBP, or CRP concentrations were found in the two groups. An enhanced acute phase response has also been reported in other groups of cancer patients ${ }^{25}$ which suggests that the presence of the tumour probably induces a general inflammatory response irrespective of tumour type. Another explanation for the small differences in inflammatory mediators might be the enhanced concentration of cortisol in patients with SCLC compared with NSCLC. Cortisol concentrations rise during periods of stress and inflammation and can attenuate the inflammatory response. ${ }^{26}$ Enhanced concentrations of inflammatory mediators in SCLC could therefore be reduced by cortisol. Evidence for this relationship could be derived from the significant correlation between plasma cortisol concentrations and concentrations of sTNF-R55 and LBP in the present study.

In conclusion, an increased REE, adjusted for FFM, occurred in patients with SCLC compared with those with NSCLC. Tumour stage did not influence the metabolic parameters in SCLC. The inflammatory mediators were enhanced in both groups of patients compared with healthy controls. These data suggest that the metabolic disturbances in both SCLC and NSCLC are influenced by similar inflammatory mechanisms.

This work was supported by the Netherlands Organization for Scientific Research (NWO), grant no. 900-562-110.

1 De Wyss WD, Begg D, Lavin PT. Prognostic effect of weight loss prior to chemotherapy in cancer patients. Am F Med 1980;69:491-7.

2 Kern KA, Norton JA. Cancer cachexia. IPEN 1988;12: 286-95.
3 Van Eys J. Effect of nutritional status on response to therapy. Cancer Res 1982;42:747-53s.

4 Staal-van den Brekel AJ, Schols AMWJ, ten Velde GPM Buurman WA, Wouters EFM. Analysis of the energy balance in lung cancer patients. Cancer Res 1994;54:64304.

5 Russell DMcR, Shike M, Marliss EB, Detsky AS, Shepherd FA, Feld R, et al. Effects of total parenteral nutrition and chemotherapy on the metabolic derangements in small cell lung cancer. Cancer Res 1984;44:1706-11.

$6 \mathrm{Jebb}$ SA, Osborne RJ, Dixon AK, Bleehen NM, Elia M. Measurements of resting energy expenditure and body composition before and after treatment of small cell lung cancer. Ann Oncol 1994;5:915-9.

7 Hansell DT, Davies JW, Burns HJG. The effects on resting energy expenditure of different tumor types. Cancer 1986; 58:1739-44.

8 Fredrix EWHM, Wouters EFM, Soeters PB, van der Aalst ACJM, Kester ADM, von Meyenfeldt MF, et al. Resting ACJM, Kester ADM, von Meyenfeldt MF, et al. Resting energy expenditure in patients

9 Tracey KJ, Wei H, Manogue KR, Fong Y, Hesse DG, Nguyen HT, et al. Cachectin/tumor necrosis factor induces cachexia, anemia, and inflammation. I Exp Med 1988; 167:1211-27.

10 Fong Y, Moldawer, Marano M, Wei H, Barber A, Manogue $\mathrm{KR}$, et al. Cachectin/TNF or IL- $1 \alpha$ induces cachexia with redistibution of body proteins. Am $\mathcal{f}$ Physiol 1989;25 R659-65.

11 Strassman G, Fong M, Kenney JS, Jacob CO. Evidence for the involvement of Interleukin 6 in experimental cance cachexia. F Clin Invest 1992;89:1681-4.

12 Staal-van den Brekel AJ, Dentener MA, Schols AMWJ, Buurman WA, Wouters EFM. Increased resting energy expenditure and weight loss are related to a systemic inflammatory response in lung cancer patients. $f$ Chin Oncol 1995;13:2600-5.

13 Engelmann H, Aderka D, Rubinstein M, Rotman D, Wallach D. A tumor necrosis factor-binding protein purified to homogeneity from human urine protects cells from tomor necrosis factor toxicity. $\mathcal{F}$ Biol Chem 1989;264: tumor necros 80 .

14 Mountain CF. A new international staging system for lung cancer. Chest 1986;89:225-33s.

15 Patel AM, Dunn WF, Trastek VF. Staging systems of lung cancer. Mayo Clin Proc 1993;68:475-82.

16 Fredrix EWHM, Soeters PB, Von Meyenfeldt MF, Sari WHM. Measurement of resting energy expenditure in a clinical setting. Clin Nutr 1990;9:299-304.

17 Ravussin E, Bogardus C. Relationship of genetics, age and physical fitness to daily energy expenditure and fue utilization. Am f Clin Nutr 1989;49:968-75.

18 Harris JA, Benedict FG. A biometric study of basal metabolism in man. Washington DC: Carnegie Institute of Washington Publication 279, 1919.

19 Larsen K. Creatinine assay by a reaction-kinetic approach. Clin Chim Acta 1972;41:209-17.

20 Quanjer PH. Standardized lung function testing. Bull Eur Physiopathol Respir 1983;19:7-44.

21 Brockhaus M, Bar-Khayim Y, Gurwicz S, Frensdorff A, Haran N. Plasma tumor necrosis factor soluble receptors in chronic renal failure. Kidney Int 1992;42:663-7.

22 SPSS/PC + Statistics 4.0 for the IBM.PC/XT/AT and PS/ 2. New York: M J Norusis/SPSS Inc, 1990.

23 Westerterp KR, Donkers JHHLM, Fredrix EWHM, Boekhoudt P. Energy intake, physical activity and body weight: houdt P. Energy intake, physical activity and bod

24 Engelberts I, Stephens S, Francot GJM, van der Linden CJ, Buurman WA. Evidence for direct effects of soluble CJ, Buurman WA. Evidence for direct effects of soluble biological fluids. Lancet 1991;338:515-6.

25 Falconer SJ, Fearon KCH, Plester CE, Ross JA, Carter DC. Cytokines, the acute-phase response and resting energy expenditure in cachectic patients with pancreatic cancer. Ann Surg 1994;219:325-31.

26 Schaur RJ, Semmelrock HJ, Schauenstein E, Kronberge L. Tumor host relations. II. Influence of tumor extent and tumor site on plasma cortisol of patients with malignan diseases. F Cancer Res Clin Oncol 1979;93:287-92. 